\title{
Terson's Syndrome Due to Aneurismal Subarachnoid Hemorrhage
}

\author{
*S Hossain ${ }^{1}$, T Guda ${ }^{2}$, F Chowdhury ${ }^{3}$, S Hossain ${ }^{4}$
}

\begin{abstract}
Vitreous or retinal hemorrhage occurring in association with subarachnoid hemorrhage is known as Terson's syndrome. In Terson's syndrome, intracranial hemorrhages are followed by intraocular hemorrhage, classically in the subhyaloid space, but may also include subretinal, retinal, preretinal, and vitreal collections. Usually occurs in adult, but can be at any age. It may be unilateral or bilateral. Vitreous hemorrhage recovery is usually spontaneous within 6 to 12 months, otherwise vitrectomy is considered. We report a case of Terson's syndrome which was admitted in Anwer Khan Modern Medical College \& Hospital as unilateral Terson's syndrome with multiple intra retinal hemorrhage of left eye associated with Hypertension \& Diabetes Mellitus.
\end{abstract}

Key Words: Terson's syndrome, Subarachnoid hemorrhage, Intra retinal hemorrhage, Intracranial pressure.

\section{Introduction}

Terson's syndrome is defined as a hemorrhage in the eye associated with acute raise of cerebral spinal fluid pressure due to intracranial hemorrhage ${ }^{1}$. Intraretinal hemorrhage is associated with subarachnoid hemorrhage was first described by Litten in 1881, but the case described in 1900 by the French ophthalmologist Albert Terson's was named as this syndrome $2,3,4$. Now a days, according to this definition, this syndrome comprises all forms of intraocular hemorrhage associated with intracranial hemorrhage or raised intracranial pressure (ICP). Hemorrhage occurring during the course of Terson syndrome may be present in one or both eyes ${ }^{2}$. Clinical symptoms include blurred vision, which correlates with the severity of bleeding, usually with characteristic intracranial hemorrhage neurological symptoms, such as loss of consciousness and coma.

Terson's syndrome occurs in $10-20 \%$ of patients who experience subarachnoid hemorrhage, but is less likely to be associated with subdural hematoma or traumatic epidural hematoma or resulting from other causes 5 . Differential diagnosis should include another cause of intraocular hemorrhage as diabetic retinopathy, hypertension, Coat's disease etc ${ }^{2}$. Ophthalmic examinations, diagnosis, and possible treatment (mainly surgical) can reduce the likelihood of subsequent visual impairments or loss of vision.

\section{Case History}

Md. Iqbal Hossain, muslim, male, businessman, hypertensive, diabetic, non asthmatic got admitted in our hospital on 11 June 2016 with the complaints of severe 'thunder-clap' like headache which he has never experienced before on the occipital region. He also noticed blurring of vision in the left eye with double vision for 2 days. Headache persisted throughout the day and there was no significant aggravating or relieving factor. Headache was

\footnotetext{
$1 *$ Prof. Dr. Sanwar Hossain, Professor\& Head, Department of Ophthalmology, AKMMC

${ }^{2}$ Dr. Titus Leonard Guda, Registrar, Department of Ophthalmology, AKMMC

${ }^{3}$ Dr. Forhad Chowdhury, Medical officer, Department of Ophthalmology, AKMMCH

${ }^{4} \mathrm{Dr}$. Md. Somir Hossain, Honorary Medical Officer, NIO \&H

*Corresponding Author
}

Date of submission: 16.02.2017, Date of submission: 24.04.2017

AKMMC J 2017; 8(2) : 153-156 
associated with vertigo \& vomiting. Headache was not associated with any fever, convulsion or aura. He had a history of transient loss of consciousness 2 days back.

On general examination, patient was irritable, ill looking, non anemic, acyanotic, non icteric, decubitus on choice. His pulse was $88 \mathrm{~b} / \mathrm{m}$, blood pressure $160 / 90 \mathrm{mmHg}$, respiratory rate was $16 / \mathrm{min}$.

On nervous system examination, he was oriented, GCS

(Glasgow coma scale) 15/15 with Left VI cranial nerve palsy. Other cranial nerves, Motor system, Sensory system were intact. Central nervous system examination was Normal and there was no signs of meningeal irritation.

On ocular examination significant findings mention below were found

\begin{tabular}{lll}
\hline & \multicolumn{1}{c}{ Right eye } & \multicolumn{1}{c}{ Left eye } \\
\hline $\begin{array}{l}\text { Visual acuity (BCVA) } \\
\text { Ocular motility }\end{array}$ & Foll in all gazes & $\begin{array}{l}\text { Full in all gazes but left } \\
\text { lateral gaze paralysis. }\end{array}$ \\
Anterior segment & Normal & Normal \\
Fundus & $\begin{array}{l}\text { Disc \& macula is } \\
\text { Normal. No disc } \\
\text { oedema or } \\
\text { temporal pallor }\end{array}$ & $\begin{array}{l}\text { Multiple intraretinal } \\
\text { hemorrhage, with } \\
\text { macular involvement. } \\
\text { Mild papilloedema in } \\
\text { Disc and temporal } \\
\text { pallor present. }\end{array}$ \\
\hline
\end{tabular}

Other systemic examination reveals no abnormality. On laboratory examination Complete blood count shows neutrophilic leukocytosis. Bleeding time, clotting time, Prothrombin time, APTT is normal. Fasting blood sugar: $6.5 \mathrm{mmol} / \mathrm{l}$. Blood sugar $2 \mathrm{hrs}$ after 75 gram glucose: $10.6 \mathrm{mmol} / 1$. Urine routine $\&$ microscopic examination is normal. Serum lipid profile normal. Serum creatinine $1 \mathrm{mg} / \mathrm{dl}$. Hbs Ag, HIV Ab, Anti HCV Ab \& VDRL all are negative. Ultrasonography of abdomino-pelvic organs shows mildly enlarged prostate otherwise normal.

We have done some specific investigations to reach our diagnosis. Among them are 1) Colour fundus photography showing multiple intraretinal hemorrhage on left eye and right eye is normal [Fig 1], 2) CT scan of Brain showing acute subarachnoid hemorrhage, bilateral lacunar cerebral infracts more marked in right \& small arachnoid cyst in right cerebral hemisphere [Fig 2] and 3) MDCT Angiography of Brain suggestive of an aneurysm on the right middle cerebral artery [Fig 3].

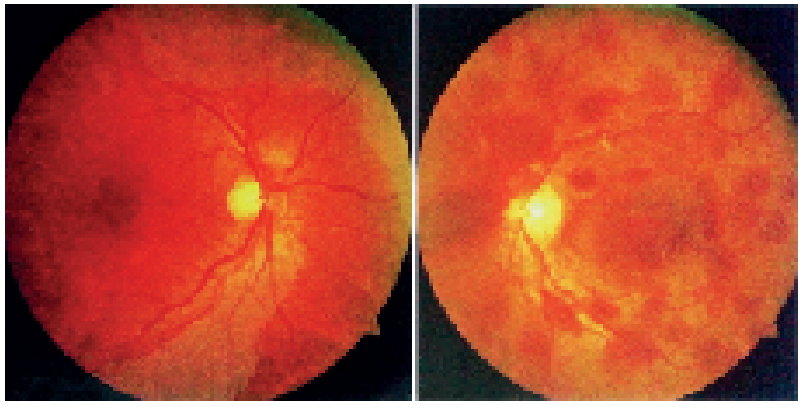

Fig.1

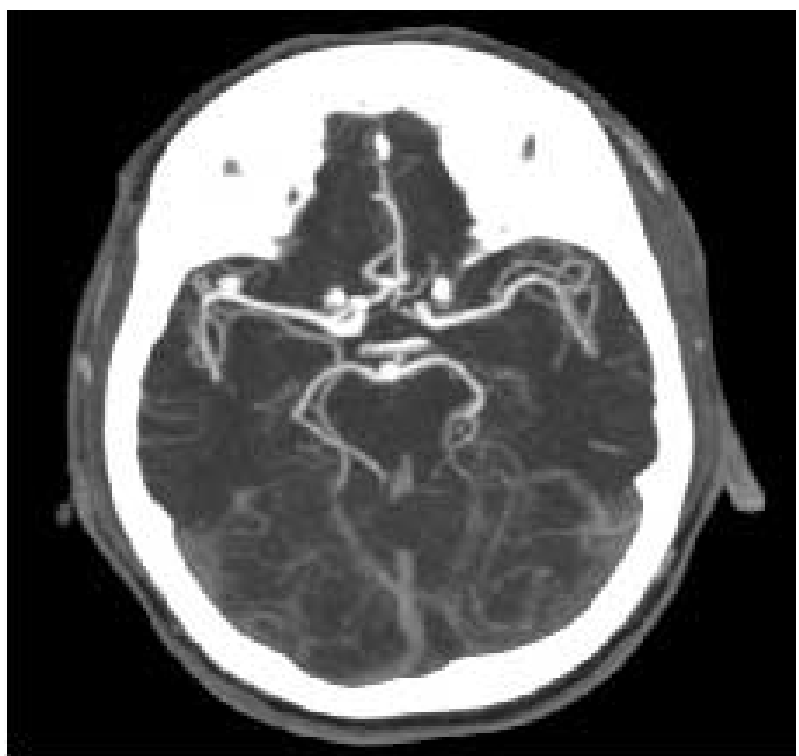

Fig. 2

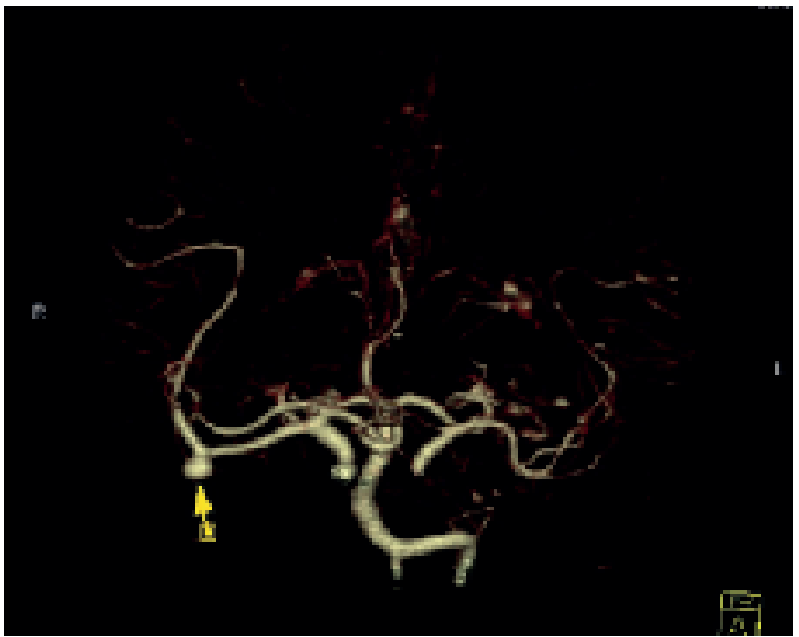

Fig. 3 
With the help of Patients history, clinical examination, laboratory investigations and radiology and imaging techniques we came to our diagnosis which is Multiple intra retinal hemorrhage (Terson's syndrome) of left eye due to rupture of middle cerebral artery aneurism with Subarachnoid hemorrhage with Hypertension and Diabetes Mellitus. Patient was treated conservatively and was adviced for neurosurgery but patient refused and discharged on risk bond.

\section{Discussion}

Occurrence of intraocular hemorrhage in association with subarachnoid hemorrhage is called Terson's Syndrome. Intraocular hemorrhage may be sub retinal, retinal, pre retinal, intra-vitreal. Usually occurs in adult, but can be at any age. Terson's syndrome occurs in $8-19.3 \%$ of subarachnoid hemorrhage $7,9,10,11,12, \quad 9.1 \%$ of intracerebral hemorrhages and $3.1 \%$ of traumatic brain injury ${ }^{2}$. $5.5 \%$ of vitreous hemorrhages not caused by diabetes or trauma are caused by Terson's syndrome ${ }^{8}$. Terson's syndrome usually occurs in adults, but has been reported in children as young as 7 months ${ }^{14,15}$. It can be unilateral or bilateral ${ }^{16}$. Terson's syndrome has been reported to be caused by or associated with multiple conditions associated with a spike in intracranial pressure. These causes include acute subarachnoid hemorrhage due to ruptured intracranial aneurism (most common), carotid artery occlusion, cortical venous sinus thrombosis ${ }^{20}$, moyamoya disease $^{21,22}$, epidural saline injection ${ }^{23}$, intra-arterial angiography, lumbosacral myelomeningocele and iaotrogenic bleeding during endoscopic third ventriculostomy ${ }^{24}$. Common site of aneurism is anterior communicating artery. Other sites are anterior cerebral artery, middle cerebral artery, posterior communicating artery. No relation between location of aneurism \& laterality of eye affected ${ }^{26}$. There are several possible pathophysiologic mechanisms for Terson's syndrome. Subarachnoid blood may be directly transmitted forward through the optic nerve sheath $^{9,7}$. More commonly a sudden increase in intracranial pressure after acute subarachnoid hemorrhage leads to rapid effusion of CSF into the optic nerve sheath. Then dilation of the retrobulbar optic nerve mechanically compresses the central retinal vein and increase venous pressure in cavernous sinus results in rupture of thin retinal vessels lead to retinal hemorrhage and leakage appears in the disc margin followed by vitreous hemorrhage. Terson's syndrome can present with hemorrhage in pre retinal space (beneath posterior vitreous face $\&$ in front of retina) Dome shaped hemorrhage in front of macula. A macular "double ring" sign may be seen with the inner ring caused sub-ILM hemorrhage and the outer ring caused by sub-hyaloid hemorrhage. Intra ocular hemorrhage frequently occurs within 1 hour of developing subarachnoid hemorrhage, delayed onset may be within 48 hours. Fundoscopic exam is the gold standard for diagnosis of Terson's syndrome but Colour fundus photograph and Fundus fluorescein angiography plays an important role in diagnosis. Bscan may be used to confirm vitreous hemorrhage when no view of funds is present. Other investigations like CT-scan of brain, MDCT angiography of brain, Lumbar puncture, MRI/ MRA are very helpful. Intraocular hemorrhage frequently resolves spontaneously1. Vision loss is usually reversible but permanent impairment of vision can occur ${ }^{15}$. It has been reported that about $50 \%$ of vitreous hemorrhages do not resolve after 19 months. There is no consensus on optimal timing for vitrectomy in Terson's syndrome. Vitreous hemorrhage can be observed for up to 3 months before considering pars plana vitrectomy (if no complication) $)^{9,25}$. In case of Terson's Syndrome due to aneurismal rupture there are some surgical treatment options for aneurysm. They are surgical clipping, endovascular coiling and artery occlusion $\&$ bypass.

\section{Conclusion}

Terson's syndrome is a rare disease in our country. The outcome of Terson's syndrome with subarachnoid hemorrhage is poor. Mortality rate is more than $30 \%$. Prognosis of vision recovery in surviving patients is relatively good and spontaneous resolution of hemorrhage within months. For proper diagnosis combined effort of Ophthalmologist, Neurologist and Radiologist is required.

\section{Interest of conflict: None}




\section{References}

1. Bin JX, Qian SL. Terson syndrome with no cerebral hemorrhage: A case report. Experimental and Therapeutic Medicine 2014; 7: 251-253.

2. Czaplicka E, Grabska-Liberek I, Rospond I, Kocicki J. Zespól Tersona omówienie przypadków klinicznych i postepowania leczniczego. Borgis Postepy Nauk Medycznych 2013; 12: 901-903.

3. Ou RJr, Talavera F,Charles S, Roy H, Phillpotts B, Yoshizumi M.Terson Syndrome treatment and management. Med Scape 2014; 13: 312-318.

4. Sánchez Ferreiro AV, Muñoz Bellido L. Atypical presentation of Terson syndrome, Presentation of a case. Neurologia 2012; 27: 380-381.

5. Browning D. What you should know about Terson's syndrome. Retinareference 2013; 1: 121

6. AAO One Network Images. one.aao.org/ images/terson-syndrome

7. Czorlich P, Skevas C, Knospe V, et al. Terson syndrome in subarachnoid hemorrhage, intracerebral hemorrhage, and traumatic brain injury. Neurosurg Rev. Epub 2014 Aug 31.

8. Skevas C, Czorlich P, Knospe V, et al. Terson's syndrome--rate and surgical approach in patients with subarachnoid hemorrhage: a prospective interdisciplinary study. Ophthalmology. 2014 Aug;121(8):1628-33.

9. Iuliano L, Fogliato G, Codenotti M. Intrasurgical imaging of subinternal limiting membrane blood diffusion in terson syndrome. Case Rep Ophthalmol Med. 2014; 2014: 689793.

10. Michalewska Z, Michalewski J, Nawrocki J. Possible methods of blood entrance in Terson syndrome. Ophthalmic Surg Lasers Imaging. 2010 Nov-Dec; 41 Suppl: S42-9.

11. Morris R., Kuhn F., and Witherspoon C.D.: Hemorrhagic macular cysts. Ophthalmology 1994

12. Morris R., Kuhn F., Witherspoon C.D., et al: Hemorrhagic macular cysts in Terson's syndrome and its implications for macular surgery. Dev Ophthalmol 1997; 29: pp. 44-54.

13. Verbraeken H, Van Egmond J. Non-diabetic and non-oculotraumatic vitreous haemorrhage treated by pars plana vitrectomy. Bull Soc Belge Ophtalmol. 1999; 272: 83-9.

14. Bhardwaj G., Jacobs M.B., Moran K.T., and Tan K.: Terson syndrome with ipsilateral severe hemorrhagic retinopathy in a 7 -month-old child. J AAPOS 2010; 14: pp. 441-443.
15. Kapoor S. Terson syndrome: an often overlooked complication of subarachnoid hemorrhage. World Neurosurg. 2014 Jan; 81(1): e4.

16. Ritland JS, Syrdalen P, Eide N, Vatne HO, Øvergaard R. Outcome of vitrectomy in patients with Terson syndrome. Acta Ophthalmol Scand. 2002 Apr; 80(2): 172-5.

17. Ogawa $\mathrm{T}$, Kitaoka $\mathrm{T}$, Dake $\mathrm{Y}$, Amemiya $\mathrm{T}$. Terson syndrome: a case report suggesting the mechanism of vitreous hemorrhage. Ophthalmology. 2001 Sep; 108(9): 1654-6.

18. Gress DR, Wintermark M, Gean AD. A case of Terson syndrome and its mechanism of bleeding. $\mathrm{J}$ Neuroradiol. 2013 Oct; 40(4): 312-4.

19. Ogawa T, Kitaoka T, Dake Y, Amemiya T. Terson syndrome: a case report suggesting the mechanism of vitreous hemorrhage. Ophthalmology. 2001 Sep; 108(9): 1654-6.

20. Takkar A, Kesav P, Lal V, Gupta A. Teaching NeuroImages: Terson syndrome in cortical venous sinus thrombosis. Neurology. 2013 Aug 6; 81(6): e40-1.

21. Kim HS, Lee SW, Sung SK, Seo EK. Terson syndrome caused by intraventricular hemorrhage associated with moyamoya disease. J Korean Neurosurg Soc. 2012 Jun; 51(6): 367-9.

22. Arakawa Y, Goto Y, Ishii A, Ueno Y, Kikuta K, Yoshizumi H, Katsuta H, Kenmochi S, Yamagata S. Terson syndrome caused by ventricular hemorrhage associated with moyamoya disease-case report. Neurol Med Chir (Tokyo). 2000 Sep; 40(9): 480-3.

23. Naseri A, Blumenkranz MS, Horton JC. Terson's syndrome following epidural saline injection. Neurology. 2001 Jul 24; 57(2): 364.

24. Hoving EW, Rahmani M, Los LI, Renardel de Lavalette VW. Bilateral retinal hemorrhage after endoscopic third ventriculostomy: iatrogenic Terson syndrome. J Neurosurg. 2009 May; 110(5): 858-60.

25. Fountas KN, Kapsalaki EZ, Lee GP, et al. Terson hemorrhage in patients suffering aneurysmal subarachnoid hemorrhage: predisposing factors and prognostic significance. J Neurosurg. 2008 Sep;109(3): 439-44.

26. A.A.O. November, 2014. Original article - Tahira Mathen, M.D. 